\title{
Bandwidth Performances of Reconfigurable Reflectarrays: State of Art and Future Challenges
}

\author{
Sandra COSTANZO, Francesca VENNERI, Giuseppe DI MASSA, Antonio BORGIA, Antonio RAFFO \\ DIMES, University of Calabria, Via P. Bucci cubo 42C, 87036 Rende (CS), Italy \\ costanzo@dimes.unical.it
}

Submitted February 12, 2018 / Accepted February 12, 2018

\begin{abstract}
Reconfigurable antennas allow to meet the increasing demands of modern RF communication systems for reconfiguration capabilities, such as beam-steering, multi-band operation, polarization flexibility or frequency agility. Active reflectarrays may represent a valuable solution to satisfy the above tasks. This paper reviews several experimental implementations of reconfigurable reflectarray designs developed in recent years. The paper describes the approaches adopted in the realization of active reflectarray designs, mainly focusing on their bandwidth performances. Future challenges in the design of wideband reconfigurable reflectarrays are also outlined.
\end{abstract}

\section{Keywords}

Reflectarrays, reconfigurable antennas, bandwidth

\section{Introduction}

Nowadays, reconfigurable antennas are employed in several modern radio frequency (RF) systems demanding for multi-functionality, adaptability and versatility. An increasing number of wireless and sensing applications, including radars, point-to-point terrestrial links and satellite communications, require one or more reconfiguration capabilities, such as beam steering/reshaping, frequency and/or polarization agility, as well as multi-band operation.

Several communication systems, starting from the well-established radar systems up to the next-generation $5 \mathrm{G}$ communication networks, require phased array antennas or mechanical moved reflectors as transmission/reception modules able to dynamically reconfigure their radiation features. Phased arrays integrate the actual radiating structure, consisting of an array of elementary antennas, with a beam-former module composed by phase shifters, active power amplifiers, and switches [1]. These additional devices provide electronic flexibility in the array excitation, thus offering the capabilities to dynamically steer/reconfigure the beam pattern. Conversely, traditional reflectors require mechanical scanning systems or more sophisticated feeding systems to realize the adaptive beam-steering/shaping functions.
An appealing alternative to traditional phased arrays and reflector antennas is offered by reconfigurable reflectarrays. They consist of an array of microstrip radiators illuminated by a feed antenna [2]. Each reflectarray element is designed to compensate for the phase delay in the path coming from the feed, while introducing, at the same time, a phase contribution to give prescribed radar beam directions and/or shapes. Reconfigurable reflectarrays are usually implemented by integrating each passive unit cell with tunable discrete components or materials able to actively tune the reflection phase, such as pin/varactor diodes, Micro Electro-Mechanical Systems (MEMS), liquid crystal (LC) or graphene-based substrates [2-4].

Several papers, recently appeared in the literature, show the effectiveness of reflectarrays in satisfying the increasing demands of modern RF communication systems for reconfiguration capabilities [3]. As a matter of fact, active reflectarrays offer several advantages over conventional phased arrays, such as reduced costs and volume, simpler architectures, and increased efficiencies due to spatial feeding mechanism. Furthermore, reflectarrays offer significant benefits over traditional reflector antennas. In fact, the combined use of the spatial feeding approach with the microstrip technology leads to high-efficiency antennas with low profiles and reduced mass.

Despite all the above mentioned benefits, reflectarrays are usually characterized by narrow operating bandwidths, caused by the intrinsic narrow-band of microstrip radiators and the differential spatial phase delays from the feed to the reflecting elements [2], [5]. Many solutions have been presented in literature [2] to enhance the operating band of passive reflectarrays. Improved bandwidths up to $19 \%$ are demonstrated in several designs [2], [6-12]. Conversely, the development of new strategies able to improve the bandwidth of active unit cells is an ongoing challenge in the reflectarray antenna design. As a matter of the fact, most existing active configurations are characterized by few percent bandwidths [2-4].

This paper reports an overview of the main approaches used to design reconfigurable reflectarray antennas, focusing on their bandwidth performances and pointing out the enhancements offered by some specific reflectarray topologies. Furthermore, the paper discusses 
future challenges in the design of wideband reconfigurable reflectarray.

The paper is organized as follows. Reflectarrays bandwidth limitations are discussed in Sec. 2, by exploring several solutions implemented for the passive case. Section 3 shows a detailed overview of various reconfigurable reflectarray configurations. The bandwidth performances of some active reflectarray designs are discussed in Sec. 4. Finally, Section 5 describes a promising dual layer varactor driven unit cell, able to offer improved bandwidth performances with respect to the existing varactor-based reflectarray configurations [2-4].

\section{Reflectarray Bandwidth Limitation and Available Solutions}

Reflectarrays combine the best features of microstrip technology with those related to parabolic reflectors. As a matter of the fact, reflectarrays are low profile antennas, characterized by a very cheap fabrication process, also offering higher efficiencies due to the spatial feeding approach (Fig. 1). As counterpart to the above benefits, reflectarrays usually operate over small frequency bands, mainly due to the frequency dependence of the spatial phase delay in the paths from feed to each array element and to the limited bandwidth of microstrip radiators [5]. The first effect is dominant for reflectarrays with large aperture sizes $D$ and small focal distances $F$ from the feed (Fig. 1), resulting in reduced $F / D$ ratios (typically $F / D \leq 0.6)$. Conversely, in the case of reflectarrays with moderate aperture dimension and $\mathrm{F} / \mathrm{D}$ ratio greater than 0.6 , the dominant factor limiting reflectarray bandwidth is the unit cell operating band [2].

The first limiting factor, the differential spatial phase delay, can be explained by referring to Fig. 1(b), where an axial-fed reflectarray is depicted, having a focal distance $F$. The feed produces a spherical wave impinging on the reflectarray aperture. Considering the paths difference $\Delta R(x, y)$ between the focal distance $F$ and each ray departing from the feed up to the generic $(x, y)$-element, a differential phase delay is produced on each array position:

$$
\begin{aligned}
\varphi_{\text {inc }}(x, y, f)= & \frac{2 \pi}{c_{0}} f \Delta R(x, y)= \\
& -\frac{2 \pi}{c_{0}} f\left(\sqrt{F^{2}+x^{2}+y^{2}}-F\right)
\end{aligned}
$$

where $c_{0}$ is the light velocity in vacuum and $f$ is the operating frequency. Each reflectarray element must be designed in order to compensate for the phase delay (1) and to steer the main beam along a desired direction or to properly shape the antenna radiation pattern, at a given central frequency $f_{0}[2]$.

For simplicity, the case of a broadside pencil-beam reflectarray is considered, for which the compensating phase (a)

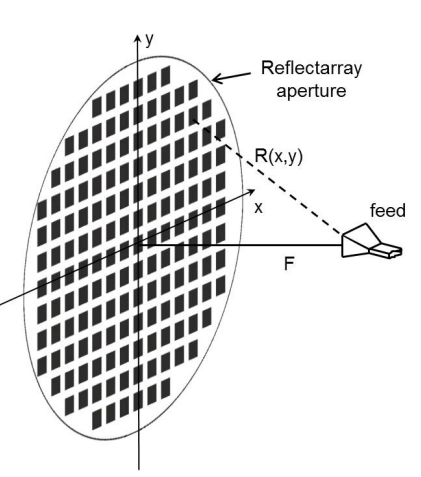

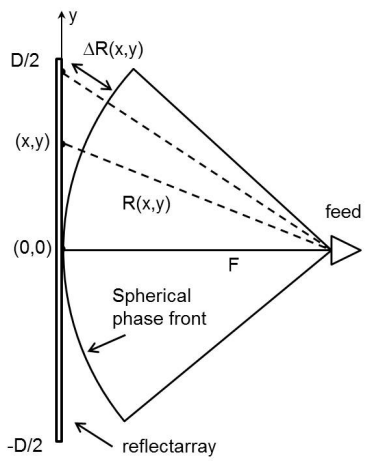

(b)
Fig. 1. Reflectarray geometry and the differential spatial phase delay: (a) 3D view; (b) side view.

introduced by each array element at $f_{0}$ must be equal to:

$$
\phi_{\text {refl }}\left(x, y, f_{0}\right)=\frac{2 \pi}{c_{0}} f_{0}\left(\sqrt{F^{2}+x^{2}+y^{2}}-F\right) .
$$

The above phase compensation guarantees the fulfillment of the imposed reflectarray design constraints only at the central frequency $f_{0}$, thus introducing a frequency excursion error in the reradiated phase front, that is so much larger the more the working frequency shifts from $f_{0}$ :

$$
\phi_{\mathrm{err}}(x, y, f)=\frac{2 \pi}{c_{0}}\left(f_{0}-f\right)\left(\sqrt{F^{2}+x^{2}+y^{2}}-F\right) .
$$

There are several methods to reduce the above excursion error $\Phi_{\text {err }}(x, y, f)$. The one is to design reflectarrays with a larger $F / D$ ratios and hence to minimize the path difference $\Delta R(x, y)$ [2], [5]. The second method is to use true time delay lines in order to compensate for the real phase delay in a range of several $360^{\circ}$ cycles [2]. This approach can be implemented using stubs with a length of several wavelengths, as demonstrated in [13]. The inconvenience of this approach is that more room is required for the delay lines allocation. Another method to increase the bandwidth of large reflectarrays is to use a concavely curved reflector with piecewise flat surfaces approximating the parabolic surface [2], [14], thus introducing a geometric compensation of feed-elements paths delays.

Conversely, in the case of moderate size reflectarrays, the dominant factor limiting the reflectarrays bandwidth is the frequency band of the single radiating element [2], [5]. As a consequence of this, the design of wideband reflectarray unit cells is the first task to be satisfied to enhance the overall reflectarrays bandwidth. A wideband operation mode can be obtained only if the adopted unit cells are able to exactly compensate for the phase delay (1) in a rather wide neighborhood of $f_{0}$. To this end, the reflection phase curves of each reflectarray element must be smooth and almost parallel in a broad range around the central operating frequency $f_{0}[2]$.

Many solutions have been proposed to improve the bandwidth performances of passive reflectarray elements (Fig. 2). They are usually based on the use of multi resonant 


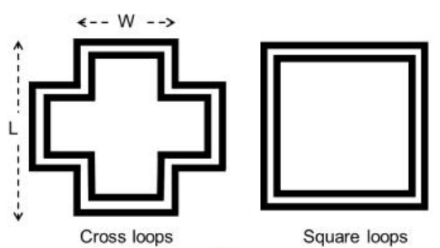

(a)

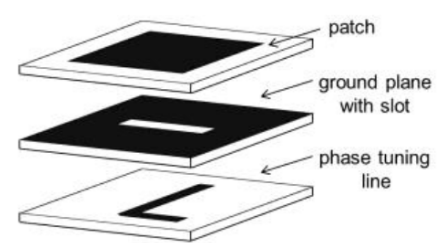

(c)

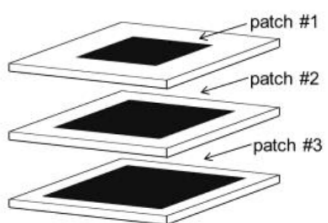

(b)

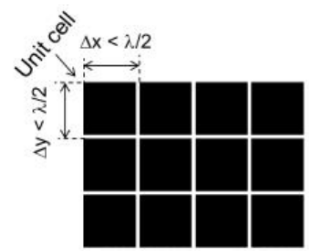

(d)
Fig. 2. Broadband passive reflectarray configurations: (a) multi-resonant concentric loops of variable size [6]; (b) variable size stacked patches [7], [8]; (c) aperturecoupled patch with lines and slots of variable length [9]; (d) closely spaced microstrip radiators [10]-[12].

elements, such as the concentric microstrip loops [6] (Fig. 2(a)) and the dual or three-layer stacked patches (Fig. 2(b)), respectively proposed in [7], [8]; the adoption of the aperture coupled configuration [9] (Fig. 2(c)), or the use of closely spaced radiators [10-12], [15] (Fig. 2(d)). Improved bandwidths ranging from $8 \%$ up to $19 \%$ are demonstrated in the above passive designs.

A quite complete overview of all existing wideband reflectarray configurations is presented in [2], including the use of thicker substrates with low permittivity.

\section{Overview on Beam-Scanning and Multi-Functional Active Reflect- array Configurations}

The benefits offered by microstrip reflectarrays make this type of antennas very attractive also for applications requiring beam-scanning capabilities or pattern reshaping features, comprising the next-generation $5 \mathrm{G}$ communication systems [16]. Several reconfigurable reflectarray unit cells have been investigated in literature [2-4], even if only some of them have been experimentally validated. Different approaches are available for realizing the dynamic phase tuning mechanism of reflectarray elements, which differ significantly in terms of maturity and complexity [3].

Recently, some active reflectarray cells have also been developed to simultaneously achieve one or more reconfiguration capabilities, such as beam-scanning, multiband operation, frequency and/or polarization agility [3]. A detailed but not exhaustive overview of various reconfigurable reflectarray configurations is discussed in the following subsections. First, the available design approaches for realizing beam-scanning reflectarrays are illustrated, and then some unit cell configurations able to meet the multi-functionality demands of modern RF applications are discussed.

\subsection{Beam-Scanning Reflectarray Approaches}

Several active phase tuning approaches have been proposed in the last two decades for beam-steering reflectarrays. They may be classified into the following groups (Fig. 3): the mechanically based approach and the electronic phase tuning approach. Both approaches are based on the idea to control the unit cells phase response by changing the features of the embedded resonators. In the first approach the elements orientation/position is changed by means of a mechanical actuation; while in the last approach an electronically-driven phase tuning mechanism is implemented, incorporating one or more variable lumped elements into the resonator or via the distributed control of tunable dielectric materials. A brief overview of some implemented active reflectarray cells, based on the abovementioned approaches, is reported in the following.

The mechanical approach (Fig. 3(a)) has been adopted in [17], [18], where miniature motors are employed to reconfigure the elements rotation [17] or the displacement of a dielectric rod under each radiator [18]. Furthermore, micro-electrical mechanical systems actuation technology is suggested in [19] to vary the height of the patches over the ground plane. The above architectures are proposed to actively reshape/scan the beam pattern. However, they suffer some limitations due to mechanical motion, such as slow reconfiguration speed and low reliability.

More recently, many other reflectarray configurations have been proposed, which are based on the use of electronically tunable microstrip elements integrated with electronic devices, such as PIN diodes, MEMs, and varactor diodes (Fig. 3(b)). The electronic approach offers faster reconfiguration speed, higher reliability, low or moderate power consumption.

Active reflectarrays based on the use of PIN-diode switches are proposed in [20-22]: a microstrip reflecting element with a single-bit phase shifter is adopted in [20] to design a large electronically reconfigurable reflectarray antenna for millimeter-wave imaging systems, operating in the $60-\mathrm{GHz}$ band; a $36.5 \mathrm{GHz}$ spiraphase-type reflectarray, based on reactively loaded ring slot resonators with switchable radial stubs, is discussed in [21], [22].

Several MEMs-based reflectarrays have been presented in literature [23-26], exploiting MEMs devices capabilities in providing both discrete as well as continuous phase control. MEMs-based reflectarray cell composed by two pseudo-rings loaded with variable digital series MEMs capacitors is fabricated and tested in [23], offering a digitally reconfigurable $360^{\circ}$-phase range at $12 \mathrm{GHz}$. A microstrip patch loaded by a slot in the ground plane, opportunely integrated with RF MEMs switches, is proposed in [24] to operate at $2 \mathrm{GHz}$. A $26.5 \mathrm{GHz}$ beam switching reflectarray, monolithically integrated with RFMEMS switches, is tested in [25]. An X-band gathered reflectarray element, having ohmic MEMS switches onto to the phasing line, is characterized and validated in [26]. 


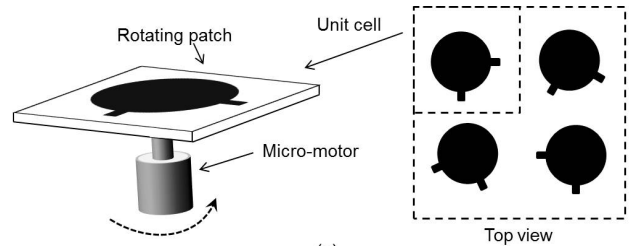

(a)

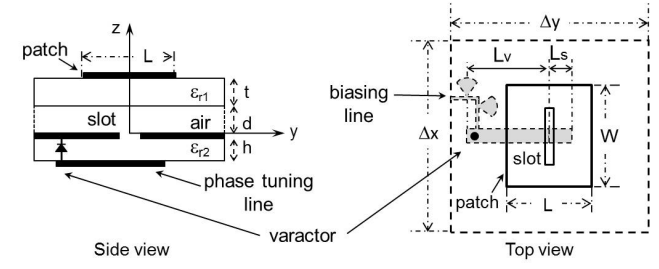

(b)

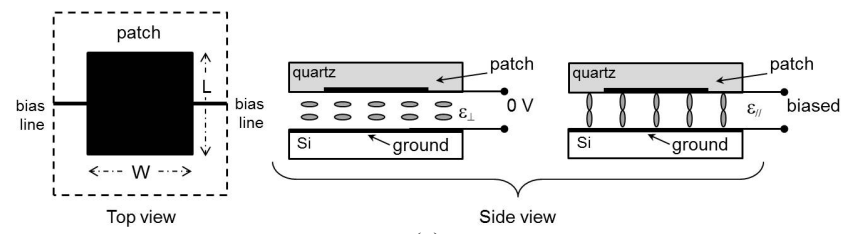

(c)

Fig. 3. Reconfigurable phase tuning approaches: (a) mechanical approach example [2]; (b) electronic phase tuning approach example based on the use of lumped electronic devices [33]; (c) electronic phase tuning approach example based on the use of tunable dielectric materials [37].

Several varactor-tuned reflectarray elements are proposed in [27-35], offering a continuous phase tuning range that allows a fine control of radiation pattern features.

A $12 \mathrm{GHz}$ microstrip dipole centrally loaded with a varactor diode is proposed in [27]. A rectangular patch loaded with a shunt connected varactor diode is discussed in [28]. A $5.8 \mathrm{GHz}$ unit cell composed by two halves of a rectangular patch, connected through two surface mounted varactors, is adopted in [29] to design a 70-elements reflectarray with beam-forming capabilities. A stubtuned reflectarray cell loaded by two varactors is demonstrated within the C-band, showing beam-steering capabilities up to $40^{\circ}$ from broadside [30]. A $5.4 \mathrm{GHz}$ unit cell consisting of a double square ring loaded with three pairs of varactor diodes is presented in [31]. Aperture-coupled patches electronically driven by a single varactor diode are designed and tested in [32-35] (Fig. 3(b)). The above aperture-coupled cells are adopted for designing two X-band reflectarrays exhibiting beam switching capabilities up to $\pm 25^{\circ}$ [33] and $\pm 45^{\circ}$ [34], respectively.

Finally, a promising approach for designing reflectarrays within the millimeter-waves and terahertz frequency ranges is based on the use of innovative tunable dielectric substrates (Fig. 3(c)), such as Liquid Crystal (LC), BariumStrontium-Titanate (BST) thick-film ceramic and graphene. A $35 \mathrm{GHz}$ tunable LC-reflectarray has been designed for the first time in [36]. Similar reflectarray designs are presented in [37], where two LC-based unit cells are designed to operate, respectively, at $102 \mathrm{GHz}$ and $130 \mathrm{GHz}$. A unit cell composed by three parallel microstrip dipoles, situated over a tunable LC-substrate, is proposed to operate at $35 \mathrm{GHz}$ [38] and within the F-band [39]. A reconfigurable folded reflectarray antenna based upon LC technology is designed at $78 \mathrm{GHz}$ in [40]. The performances of an Xband reconfigurable element based on BST thick-film ceramic are discussed in [41]. A tunable graphene-based reflective cell operating within the $\mathrm{THz}$ frequencies range is proposed in [42].

\subsection{Multi-Functional Reconfigurable Reflectarray Cells}

Recently, the effectiveness of reflectarrays in achieving one or more reconfiguration capabilities is demonstrated in literature [3]. Some reflectarray cells have been properly designed to simultaneously implement the beamscanning function with other additional reconfiguration capabilities, such as multi-band operation, polarization and/or frequency agility.

A first proof-of-concept of multiband beam-steering reflectarray is reported in [43], which describes a dualband cell $(24.4 \mathrm{GHz} / 35.5 \mathrm{GHz})$ implementing the element rotation technique through the use of MEMS switches. A circularly-polarized reflectarray cell, based on the use of two loaded microstrip split-rings integrated with RF MEMs, is adopted to design and fabricate a reflectarray exhibiting beam switching up to $\pm 35^{\circ}$ and $\pm 24^{\circ}$ in $\mathrm{K}$ and Ka bands, respectively.

A combination of surface-mounted PIN and varactor diodes is proposed in [44] to design a reflecting cell able to offer the dynamic and independent control of the reflection phase of two perpendicular linearly polarized waves. The concept is experimentally demonstrated on a unit cell operating at $8 \mathrm{GHz}$.

A reflectarray cell based on the use of a varactor and a couple of PIN diodes is presented in [45] to actively tune the reflection phase over a 50\% frequency range, from $1.88 \mathrm{GHz}$ up to $3.07 \mathrm{GHz}$, so offering a quite good degree of frequency agility.

\section{Bandwidth Performances of Beam Scanning Reflectarrays}

The reconfigurable reflectarray designs described in the above sections are usually characterized by few percent bandwidths. For this reason, further efforts are needed in the development of broadband active reflectarray radiators. Wideband reconfigurable antennas, in fact, are essential to support the high throughput required by modern applications, like future 5G communication networks [16].

Table 1 shows a quick comparison among the bandwidth performances offered by some implemented active reflectarray cells. In particular, Table 1 reports the phase 


\begin{tabular}{|c|c|c|c|}
\hline $\begin{array}{c}\text { Cell configuration } \\
\text { description }\end{array}$ & $\begin{array}{c}\text { \# of active lumped } \\
\text { elements } \\
\text { integrated to each } \\
\text { unit cell }\end{array}$ & Frequency & $\begin{array}{c}\text { Phase curve } \\
\text { bandwidth }\end{array}$ \\
\hline $\begin{array}{c}\text { Rectangular patch } \\
\text { loaded with a PIN } \\
\text { diode [20] }\end{array}$ & 1 & $60 \mathrm{GHz}$ & $0.75 \%$ \\
\hline $\begin{array}{c}\text { Single layer } \\
\text { rectangular patch } \\
\text { loaded with a } \\
\text { varactor diode [28] }\end{array}$ & 1 & $5 \mathrm{GHz}$ & $0.6 \%$ \\
\hline $\begin{array}{c}\text { Two halves } \\
\text { of a rectangular patch } \\
\text { serially connected by } \\
\text { two surface-mounted } \\
\text { varactor diodes [29] }\end{array}$ & 2 & $5.5 \mathrm{GHz}$ & $1.3 \%$ \\
\hline $\begin{array}{c}\text { Stub-tuned cell } \\
\text { loaded by two } \\
\text { varactors [30] }\end{array}$ & 2 & $5.4 \mathrm{GHz}$ & $2.2 \%$ \\
\hline $\begin{array}{c}\text { Double square ring } \\
\text { loaded with three } \\
\text { pairs of varactors [31] }\end{array}$ & 6 & $5.4 \mathrm{GHz}$ & $2.4 \%$ \\
\hline $\begin{array}{c}\text { Aperture-coupled } \\
\text { patch [33] (varactor } \\
\text { loaded linear line) }\end{array}$ & 1 & $11.25 \mathrm{GHz}$ & $1.2 \%$ \\
\hline $\begin{array}{c}\text { Aperture-coupled } \\
\text { patch [35] (varactor } \\
\text { loaded radial line) }\end{array}$ & $10 \mathrm{GHz}$ & $3 \%$ \\
\hline $\begin{array}{c}\text { Three parallel } \\
\text { microstrip dipoles } \\
\text { over a tunable } \\
\text { LC-substrate [39] }\end{array}$ & - & $35 \mathrm{GHz}$ & $7 \%$ \\
\hline
\end{tabular}

Tab. 1. Phase curve bandwidth of different reconfigurable reflectarray cells.

curve bandwidth (BW) of each configuration, usually computed as the frequency range over which the phase reflected by the cell remained within $\pm 22.5^{\circ}$ of the center of the tuning range [29], [30]. As discussed in the following, the frequency performances of some configurations, among those cited in Tab. 1, are also evaluated in terms of gain bandwidth.

At a first look, we can observe very narrow bandwidth values ranging from $0.6 \%$ up to $3 \%$, for the unit cells integrating variable lumped elements (Tab. 1), while an improved $7 \% \mathrm{BW}$ is achieved for a LC-based cell.

In particular, a $0.75 \%$-bandwidth is obtained in the case of the PIN-based configuration proposed in [24].

A very small $\mathrm{BW}$ equal to $0.6 \%$ is achieved in the case of the single layer rectangular patch shunt connected with a varactor diode [28]. This bandwidth value is consistent with a microstrip patch printed on the same substrate having a thickness $t=0.762 \mathrm{~mm}$, equal to about $\lambda_{0} / 79$ at the operating frequency $f_{0}$.

A greater $\mathrm{BW}$-value, equal to $1.3 \%$, is achieved for the single layer cell composed by two halves of a rectangular patch serially connected by two surface-mounted varactors [29]. The above bandwidth improvement is substantially due to the use of a thicker substrate that is equal to about $\lambda_{0} / 36$ at $5.5 \mathrm{GHz}[2]$.
A stub-tuned reflectarray cell loaded by two varactors is properly designed in [30] achieving a $2.2 \%$ phase bandwidth, at $5.4 \mathrm{GHz}$, and a $3 \mathrm{~dB}$-gain bandwidth equal to $3.6 \%$. This configuration allows to achieve improved BWvalues, taking advantages of the aperture coupled stacked structure. In fact, by properly exploiting the features of the different substrates composing the unit cell, namely the radiating element and the phase tuning line substrates, one can improve the antenna bandwidth leaving unchanged the phase tuning range offered by the cell. To this end, a very thick $3-\mathrm{mm}\left(\cong \lambda_{0} / 19\right)$ Rohacell 71 foam layer is adopted in [30] as a patch substrate.

A similar aperture coupled configuration is adopted by the authors in [33], [35] to design two reflectarray unit cells driven by a single varactor diode. In these designs, the integration of a single diode per cell allows to reduce both the costs as well as the complexity of the electronic controlling board. As the aim of the first design [33] was simply to demonstrate the validity of the proposed phase tuning approach, the unit cell was not optimized in terms of bandwidth, which stands to a value of about $1.2 \%$ at $11.25 \mathrm{GHz}$. Conversely, the unit cell proposed in [35] is properly designed to offer improved frequency performances. The novelty of this cell, with respect to that presented in [32], lies in the phasing line geometry that is properly modified in order to act as a wide-band phaseshifter. To this end, a couple of wideband radial stubs is adopted achieving an instantaneous bandwidth of about $3 \%$ at $10 \mathrm{GHz}$, and a $1 \mathrm{~dB}$-gain bandwidth equal to $6 \%$ [35].

Finally, by adopting the well-known approach based on the use of multi resonant elements [6], a 2.5\% bandwidth is achieved in [30] for a $5.4 \mathrm{GHz}$ single layer cell based on the use of double square ring loaded with three pairs of varactor diodes. A similar approach is adopted in [38] to design a $35-\mathrm{GHz}$ unit cell composed by three parallel microstrip dipoles, situated over a tunable LC-substrate, offering an extended $7 \%$-bandwidth with respect to the existing LC-based reflectarrays [2].

The above designs show how the adoption of the traditional approaches, employed in passive broadband reflectarrays designs (see Sec. 2), allows to slightly improve the bandwidth of reconfigurable reflectarrays (up to $3 \%$, in the case of the electronic approach based on the use of variable lumped elements, and up to $7 \%$, for the tunable dielectric materials distributed control approach - Tab. 1). However, it is evident that at present only a few studies have focused their attention on the development of broadband active reflectarray cells. Further efforts are needed in order to improve the frequency performances of this type of antenna. Multi resonant active designs, for example, could be further explored to get better performances in terms of bandwidth. At this purpose, a dual stacked resonators loaded by a single varactor diode is demonstrated in the next section, offering improved bandwidth performances with respect to the existing varactor-based reflectarray cells (Tab. 1). 


\section{Future Challenges in the Design of Wideband Reconfigurable Reflectarrays}

A novel reconfigurable reflectarray cell is proposed in this paper to overcome the intrinsic bandwidth limitations of reflectarrays. It consists of two stacked fixed size patches loaded by a single varactor diode. The proposed phase tuning mechanism allows to combine unit cell beamscanning and/or reshaping pattern capabilities with frequency reconfigurability features. Furthermore, the use of a stacked structure [7] allows to improve the instantaneous bandwidth of the antenna.

The proposed active unit cell is illustrated in Fig. 4. Two fixed size patches (Fig. 4(b)) are printed onto different stacked substrate layers, opportunely spaced each other with an air gap (Fig. 4(a)), having a thickness $h_{\text {air }}$, assuring an adequate parasitic coupling between the two patches. As depicted in Fig. 4, the lower patch is loaded with a varactor diode, so acting as a phase shifter providing a continuous phase tuning mechanism. Both patches are properly chosen to achieve a full reflection phase control at the desired frequency, by varying the diode capacitance within the values-range offered by the adopted varactor model.

In this work, the unit cell is properly designed to give a quite full phase range around $10.8 \mathrm{GHz}$, only by changing the diode capacitance $C_{\text {var }}$ from $0.2 \mathrm{pF}$ up to $2 \mathrm{pF}$. The synthesized cell (Fig. 4) consists of a lower patch $\left(L_{1} \times W_{1}=5.1 \mathrm{~mm} \times 5.1 \mathrm{~mm}\right)$ printed on a grounded dielectric slab having $h_{1}=0.762 \mathrm{~mm}$ and $\varepsilon_{\mathrm{r}}=2.33$ (i.e. Diclad870), and an upper patch $\left(L_{2} \times W_{2}=8.5 \mathrm{~mm} \times 8.5 \mathrm{~mm}\right)$ printed on a substrate composed by a $0.762-\mathrm{mm}$-thick layer of Diclad870, and a layer of air with a thickness $h_{\text {air }}=$ $0.762 \mathrm{~mm}$. The resonant side of the upper patch (i.e. $L_{2}$ ) is designed to give the resonance at $10.8 \mathrm{GHz}$, while the lower patch is sized to achieve a full phase tuning of the unit cell reflection coefficient. In order to take into account the mutual coupling effects between reflectarray elements, the unit cell analysis is performed by adopting the infinite array approach and assuming a normally incident plane wave, with a y-oriented electric field component (Fig. 4). The variable capacitive load is modeled with the equivalent

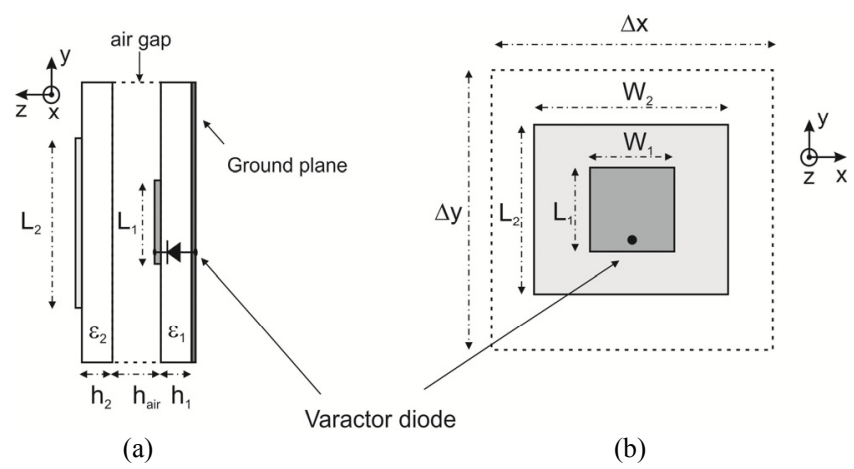

Fig. 4. Unit cell geometry: (a) side view; (b) top view.

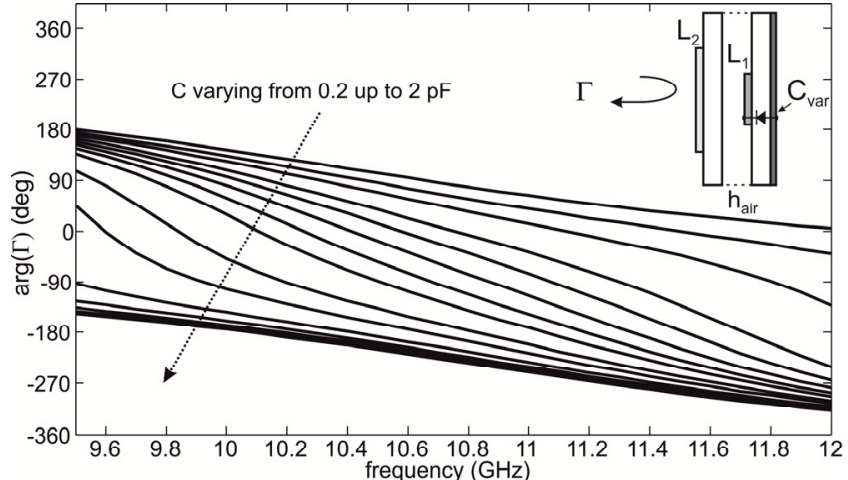

(a)

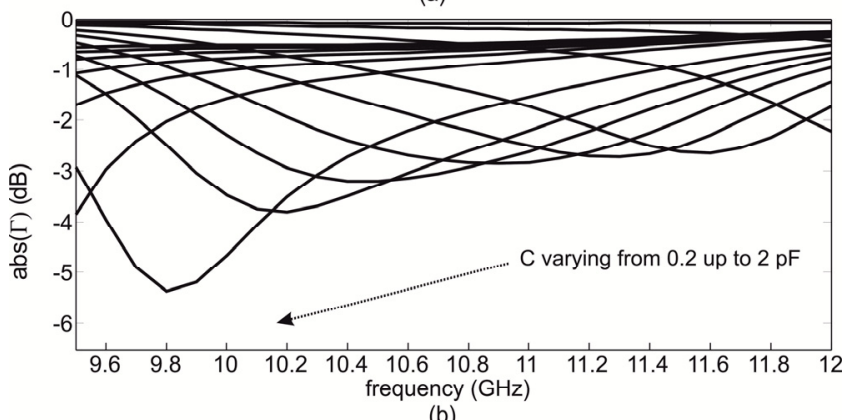

(b)

Fig. 5. Simulated reflection coefficient vs frequency for different diode capacitance: (a) phase; (b) amplitude.

circuit reported in [33], which considers the parasitic effects due to diode package, consisting of a $0.15 \mathrm{pF}$ parallel capacitance and a $0.2 \mathrm{nH}$ series inductance.

As it can be observed in Fig. 5(a), by changing the diode capacitance $C_{\text {var }}$ from $0.2 \mathrm{pF}$ up to $2 \mathrm{pF}$, a phase variation range of about $315^{\circ}$ is obtained at the design frequency $f_{0}=10.8 \mathrm{GHz}$. Furthermore, as demonstrated by the simulated phase curves reported in the same figure, the element reflection phase can be almost completely tuned also at other neighboring frequencies ranging from 9.9 up to $11.9 \mathrm{GHz}$ ( $\Delta f=2 \mathrm{GHz}$, about equal to $18.4 \%$ with respect to the central operating frequency). As a matter of the fact, each phase curve lying in this frequency span covers a phase range greater than $300^{\circ}$, thus offering the capabilities to effectively reconfigure the antenna radiation features.

Figure 5(a) also demonstrates a quite smooth reflection phase behavior against frequency, showing wideband features with respect to the existing varactor-based reflectarray cells [28-31], [33], [35]. As a matter of the fact, the computed phase curve bandwidth is equal to about $6 \%$ that is 2 times greater with respect to the BW-value demonstrated in [35]. Furthermore, Figure 5(b) shows a maximum reflection loss of about $3 \mathrm{~dB}$ in a neighborhood of the working frequency $f_{0}=10.8 \mathrm{GHz}$.

\section{Conclusions}

A detailed overview of reconfigurable reflectarrays has been presented and discussed in this paper. Several active reflectarray configurations have been described, 
focusing on their bandwidth performances and pointing out the enhancements offered by some specific reflectarray topologies. Finally, a discussion about future challenges in the design of wideband reconfigurable reflectarrays has been provided. At this purpose, a preliminary design of a dual-layer varactor loaded reflectarray cell, offering improved bandwidth performance with respect to existing varactor-based reflectarray configurations, has been illustrated. As future developments, the above cell will be tested and exploited to design a wideband beam-scanning reflectarray.

\section{References}

[1] FENN, A. J., TEMME, D. H., DELANEY, W. P., COURTNEY, W. E. The development of phased-array radar technology. Lincoln Laboratory Journal, 2000, vol. 12, no. 2, p. 321-340.

[2] HUANG, J., ENCINAR, J. Reflectarray Antennas. Wiley-IEEE Press, 2008. ISBN: 9780470084915

[3] HUM, S. V., PERRUISSEAU-CARRIER, J. Reconfigurable reflectarrays and array lenses for dynamic antenna beam control: A review. IEEE Transactions on Antennas and Propagation, 2014, vol. 62, p. 183-198. DOI: 10.1109/TAP.2013.2287296

[4] NAYERI, P., YANG, F., ELSHERBENI, A. Z. Beam-scanning reflectarray antennas: A technical overview and state of the art. IEEE Antennas and Propagation Magazine, 2015, vol. 57, no. 4, p. 32-47. DOI: 10.1109/MAP.2015.2453883

[5] POZAR, D. M. Bandwidth of reflectarrays. Electronics Letters, 2003, vol. 39, no. 21, p. 1490-1491. DOI: 10.1049/el:20030990

[6] CHAHARMIR, M., SHAKER, J., GAGNON, N., LEE, D. Design of broadband, single layer dual-band large reflectarray using multi open loop elements. IEEE Transactions on Antennas and Propagation, 2010, vol. 58, no. 9, p. 2875-2883. DOI: 10.1109/TAP.2010.2052568

[7] ENCINAR, J. A. Design of two-layer printed reflectarrays using patches of variable size. IEEE Transactions on Antennas and Propagation, 2001, vol. 49, no. 10, p. 1403-1410. DOI: $10.1109 / 8.954929$

[8] ENCINAR, J. A., ZORNOZA, J. A. Broadband design of threelayer printed reflectarrays. IEEE Transactions on Antennas and Propagation, 2003, vol. 51, no. 7, p. 1662-1664. DOI: 10.1109/TAP.2003.813611

[9] CARRASCO, E., BARBA, M., ENCINAR, J. Reflectarray element based on aperture-coupled patches with slots and lines of variable length. IEEE Transactions on Antennas and Propagation, 2007, vol. 55 , no. 3 , p. $820-825$. DOI: 10.1109/TAP.2007.891863

[10] COSTANZO, S., VENNERI, F., DI MASSA, G. Bandwidth enhancement of aperture-coupled reflectarrays. Electronics Letters, 2006, vol. 42 , no. 23 , p. 1320-1321. DOI: 10.1049/el:20062492

[11] VENNERI, F., COSTANZO, S., DI MASSA, G. Bandwidth behavior of closely spaced aperture-coupled reflectarrays. International Journal of Antennas and Propagation, vol. 2012, Article ID 846017, 2012. DOI:10.1155/2012/846017

[12] NAYERI, P., YANG, F., ELSHERBENI, A. Z. Broadband reflectarray antennas using double-layer subwavelength patch elements. IEEE Antennas and Wireless Propagation Letters, 2010, vol. 9, p. 1139-1142. DOI: 10.1109/LAWP.2010.2094178

[13] CARRASCO, E., BARBA, M., ENCINAR, J. A. Aperture-coupled reflectarray element with wide range of phase delay. Electronics
Letters, 2006, vol. 42, no. 12, p. 667-668. DOI: 10.1049/el:20060472

[14] ROEDERER, A. Reflector antenna comprising a plurality of panels. US6411255, 2002-06-25.

[15] COSTANZO, S., VENNERI, F. Miniaturized fractal reflectarray element using fixed-size patch. IEEE Antennas and Wireless Propagation Letters, 2014, vol. 13, p. 1437-1440. DOI: 10.1109/LAWP.2014.2341032

[16] DAHARI, M. H., JAMALUDDIN, M. H., ABBASI, M. I., KAMARUDIN, M. R. A review of wideband reflectarray antennas for 5G communication systems. IEEE Access, 2017, vol. 5, p. 17803-17815. DOI: 10.1109/ACCESS.2017.2747844

[17] HUANG, J., POGORZELSKI, R. J. A Ka-band microstrip reflectarray with elements having variable rotation angles. IEEE Transactions on Antennas and Propagation, 1998, vol. 46, no. 5, p. 650-656. DOI: 10.1109/8.668907

[18] COOLEY, M. E., WALKER, J. F., GONZALEZ, D. G., POLLON, G. E. Novel reflectarray element with variable phase characteristics. IEE Proceedings - Microwaves, Antennas and Propagation, 1997, vol. 144, no. 2, p. 149-151. DOI: 10.1049/ip-map:19970963

[19] GIANVITTORIO, J. P., RAHMAT-SAMII, Y. Reconfigurable patch antennas for steerable reflectarray applications. IEEE Transactions on Antennas and Propagation, 2006, vol. 54, no. 5, p. 1388-1392. DOI: 10.1109/TAP.2006.874311

[20] KAMODA, H., IWASAKI, T., TSUMOCHI, J., KUKI, T. 60-GHz electrically reconfigurable reflectarray using $\mathrm{p}$-i-n diode. In IEEE MTT-S International Microwave Symposium Digest. Boston (MA, USA), 2009, p. $1177-1180$. DOI: 10.1109/MWSYM.2009.5165912

[21] RODRIGUEZ-ZAMUDIO, J., MARTINEZ-LOPEZ, J. I., RODRIGUEZ-CUEVAS, J., MARTYNYUK, A. E. Reconfigurable reflectarrays based on optimized spiraphase type elements. IEEE Transactions on Antennas and Propagation, 2012, vol. 60, no. 4, p. 1821-1830. DOI: 10.1109/TAP.2012.2186231

[22] SILVA-MONTERO, J., MARTINEZ-LOPEZ, J. I., RODRIGUEZ-CUEVAS, J., MARTYNYUK, A. E. Spiraphase-type reflectarray for large reflection elevation angles. IEEE Transactions on Antennas and Propagation, 2015, vol. 63, no. 10, p. 4342-4351. DOI: 10.1109/TAP.2015.2456981

[23] PERRUISSEAU-CARRIER, J., SKRIVERVIK, A. K. Monolithic MEMS-based reflectarray cell digitally reconfigurable over a 360 phase range. IEEE Antennas and Wireless Propagation Letters, 2008, vol. 7, p. 138-141. DOI: 10.1109/LAWP.2008.919327

[24] RAJAGOPALAN, H., RAHMAT-SAMII, Y., IMBRIALE, W. RF MEMs actuated reconfigurable reflectarray patch-slot element. IEEE Transactions on Antennas and Propagation, 2008, vol. 56, no. 12, p. 3689-3699. DOI: 10.1109/TAP.2008.2007388

[25] BAYRAKTAR, O., CIVI, O. A., AKIN, T. Beam switching reflectarray monolithically integrated with RF MEMS switches. IEEE Transactions on Antennas and Propagation, 2012, vol. 60, no. 2 , p. $854-862$. DOI: 10.1109/TAP.2011.2173099

[26] CARRASCO, E., BARBA, M., REIG, B., DIEPPEDAlE, C., ENCINAR, J. Characterization of a reflectarray gathered element with electronic control using ohmic RF MEMS and patches aperture-coupled to a delay line. IEEE Transactions on Antennas and Propagation, 2012, vol. 60, no. 9, p. 4190-4201. DOI: 10.1109/TAP.2012.2207046

[27] VENDIK, O., PARNES, M. A phase shifter with one tunable component for a reflectarray antenna. IEEE Antennas and Propag. Magazine, 2008, vol. 50, no. 4, p. 53-65. DOI: 10.1109/MAP.2008.4653662

[28] BOCCIA, L., AMENDOLA, G., DI MASSA, G. Performance improvement for a varactor loaded reflectarray element. In The 2nd 
European Conference on Antennas and Propagation EuCAP 2007. Edinburgh (U.K.), 2007. DOI: 10.1049/ic.2007.1617

[29] HUM, S. V., OKONIEWSKI, M., DAVIES, R. J. Modeling and design of electronically tunable reflectarrays. IEEE Transactions on Antennas and Propagation, 2007, vol. 55, no. 8, p. 2200-2210. DOI: 10.1109/TAP.2007.902002

[30] RIEL, M., LAURIN, J. J. Design of an electronically beam scanning reflectarray using aperture-coupled elements. IEEE Transactions on Antennas and Propagation, 2007, vol. 55, no. 5, p. 1260-1266. DOI: 10.1109/TAP.2007.895586

[31] LIU, C., HUM, S. An electronically tunable single-layer reflectarray antenna element with improved bandwidth. IEEE Antennas and Wireless Propagation Letters, 2010, vol. 9, p. 1241-1244. DOI: 10.1109/LAWP.2011.2104934

[32] VENNERI, F., COSTANZO, S., DI MASSA, G. Reconfigurable aperture coupled reflectarray element tuned by a single varactor diode. Electronics Letters, 2012, vol. 48, p. 68-69. DOI: 10.1049/el.2011.3691

[33] VEnNERI, F., COSTANZO, S., DI MASSA, G. Design and validation of a reconfigurable single varactor-tuned reflectarray. IEEE Transactions on Antennas and Propagation, 2013, vol. 61, no. 2, p. 635-645. DOI: 10.1109/TAP.2012.2226229

[34] VENNERI, F., COSTANZO, S., DI MASSA, G. Tunable reflectarray cell for wide angle beam-steering radar applications. Journal of Electrical and Computer Engineering, vol. 2013, article ID 325746,7 pages. DOI:10.1155/2013/325746.

[35] COSTANZO, S., VENNERI, F., RAFFO, A., DI MASSA, G., CORSONELLO, P. Radial-shaped single varactor-tuned phasing line for active reflectarrays. IEEE Transactions on Antennas and Propagation, 2016, vol. 64, no. 7, p. 3254-3259. DOI: 10.1109/TAP.2016.2562673

[36] MOESSINGER, A., MARIN, R., MUELlER, S., FREESE, J., JAKOBY, R. Electronically reconfigurable reflectarrays with nematic liquid crystals. Electronics Letters, 2006, vol. 42, no. 16, p. 899-900. DOI: 10.1049/el:20061541

[37] HU, W., CAHILL, R., ENCINAR, J., DICKIE, R., GAMBLE, H., FUSCO, V., GRANT, N. Design and measurement of reconfigurable millimeter wave reflectarray cells with nematic liquid crystal. IEEE Transactions on Antennas and Propagation, 2008, vol. 56, no. 10 , p. $3112-3117$. DOI: 10.1109/TAP.2008.929460

[38] PEREZ-PALOMINO, G., ENCINAR, J., BARBA, M., CARRASCO, E. Design and evaluation of multi-resonant unit cells based on liquid crystals for reconfigurable reflectarrays. IEE Proceedings - Microwaves, Antennas and Propagation, 2012, vol. 6, no. 3, p. 348-354. DOI: 10.1049/iet-map.2011.0234

[39] PEREZ-PALOMINO, G., BAINE, P., DICKIE, R., BAIN, M., ENCINAR, J., CAHILL, R., BARBA, M., TOSO, G. Design and experimental validation of liquid crystal based reconfigurable reflectarray elements with improved bandwidth in F-band. IEEE Transactions on Antennas and Propagation, 2013, vol. 61, no. 4, p. 1704-1713. DOI: 10.1109/TAP.2013.2242833

[40] BILDIK, S., DIETER, S., FRITZSCH, C., MENZEL, W., JAKOBY, R. Reconfigurable folded reflectarray antenna based upon liquid crystal technology. IEEE Transactions on Antennas and Propagation, 2015, vol. 63, no. 1, p. 122-132. DOI: 10.1109/TAP.2014.2367491

[41] SAZEGAR, M., GIERE, A., ZHENG, Y., MAUNE, H., MOESSINGER, A., JAKOBY, R. Reconfigurable unit cell for reflectarray antenna based on barium-strontium-titanate thick-film ceramic. In Proceedings of the 39th European Microwave Conference (EuMC 2009). Rome (Italy), 2009, p. 598-601. DOI: 10.23919/EUMC.2009.5296104

[42] CARRASCO, E., PERRUISSEAU-CARRIER, J. Reflectarray antenna at terahertz using graphene. IEEE Antennas and Wireless
Propagation Letters, 2013, vol. 12, p. 253-256. DOI: 10.1109/LAWP.2013.2247557

[43] GUClu, C., PERruisseau-CARrier, J., AYDIN CIVI, O. Proof of concept of a dual band circularly polarized RF MEMS beam switching reflectarray. IEEE Transactions on Antennas and Propagation, 2012, vol. 60, no. , p. 5451-5455. DOI: 10.1109/TAP.2012.2207690

[44] PERRUISSEAU-CARRIER, J. Dual-polarized and polarizationflexible reflective cells with dynamic phase control. IEEE Transactions on Antennas and Propagation, 2010, vol. 58, no. 5, p. 1494-1502. DOI: 10.1109/TAP.2010.2044333

[45] RODRIGO, D., JOFRE, L., PERRUISSEAU-CARRIER, J. Unit cell for frequency-tunable beams canning reflectarrays. IEEE Transactions on Antennas and Propagation, 2013, vol. 61, no. 12, p. 5992-5999. DOI: 10.1109/TAP.2013.2281375

\section{About the Authors ...}

Sandra COSTANZO received the Laurea degree (summa cum laude) in Computer Engineering from the University of Calabria in 1996, and the Ph.D. degree in Electronic Engineering from the University of Reggio Calabria in 2000. Currently, she is an Associate Professor at University of Calabria, Italy, where she teaches the courses of electromagnetic waves propagation, remote sensing and radar systems and electromagnetic diagnostics. At the same University, she is the Coordinator of Master Degree Course in Telecommunication Engineering.

Since 1996, she has been involved in many research projects funded by ESA (European Space Agency), ASI (Agenzia Spaziale Italiana), MIUR (Ministero dell'Istruzione, dell'Università e della Ricerca) and private companies. She is Senior Member of IEEE, member of IEEE South Italy Geoscience and Remote Sensing Chapter, CNIT (Consorzio Nazionale Interuniversitario per le Telecomunicazioni) and SIEm (Società Italiana di Elettromagnetismo), and Board Member of IEEEAP/ED/MTT North Italy Chapter, and of IEEE Information Theory Italy Chapter. She is Associate Editor of IEEE Antennas and Wireless Propagation Letters, IEEE Access and Radioengineering journals.

Her research interests are focused on near-field far-field techniques, antenna measurement techniques, antenna analysis and synthesis, numerical methods in electromagnetics, millimeter-wave antennas, reflectarrays, synthesis methods for microwave structures, electromagnetic characterization of materials, innovative antennas and technologies for radar applications.

She has been Editor of two books and Lead Editor of three special issues on international journals. She has (co) authored more than 160 contributions in international journals, books and conferences.

Francesca VENNERI received the degree in Information Technology Engineering from the University of Calabria, Italy, in 1998 and the Ph.D. degree in Electronic Engineering from the University "Mediterranea" of Reggio 
Calabria in 2002. Currently, she is an Assistant Professor at the University of Calabria. Her research interests focus on microstrip reflectarrays, antenna analysis and synthesis, RFID technology, metamaterial absorbers. She is member of the IEEE Antennas and Propagation Society, the SIEm (Società Italiana di Elettromagnetismo) and the CNIT (Consorzio Nazionale Interuniversitario per le Telecomunicazioni).

Giuseppe DI MASSA was born in Barano d'Ischia, Naples, Italy, in 1948. He received the Laurea degree in Electronic Engineering from the University of Naples, Federico II, Naples, Italy, in 1973.

From 1978 to 1979, he was Professor of Antennas at the University of Naples, Italy. In 1980, he joined the University of Calabria, Italy, as Professor of Electromagnetic Waves. Since 1985, he served as an Associate Professor, and since 1994 as a Full Professor, at the same university, where he teaches antennas and electromagnetic fields. From 1985 to 1986 he was a Scientific Associate at CERN, Geneva. In 1988, he was Visiting Professor at Brookhaven National Laboratory, Long Island, NY. From 1997 to 2002, he was the Dean of the Department of Elettronica, Informatica and Sistemistica and the President of Programming Committee at the University of Calabria. From 2000 to 2017 he was the Chairman of the Telecommunication Engineering Program at the University of Calabria.

He was the Italian Delegate in the European COST 284 "Innovative Antennas for Emerging Terrestrial and SpaceBased Applications from 2002 to 2006 and, from 2007 to 2011, in the COST Action IC0603: Antenna Systems \& Sensors for Information Society Technologies (ASSIST). From 2011 to 2014 was the Italian delegate in the Management Committee of the COST Action IC1102, Versatile Integrated and Signal-aware Technologies for Antennas (VISTA). From 2003 to 2007, he participated in the Network of Excellence Antenna Centre of Excellence (ACE), where he was part of the Governing Board and leader of Work Group WP 1.2-1: Antenna Measurement Services.

He has authored/coauthored more than 300 scientific papers, mainly on international scientific journals or proceedings of international conferences. He is the Principal Investigator or Coordinator of many research programs, granted by national and international research organizations, as well as by leading national companies. His main research interests are focused on applied computational electromagnetics, microstrip antennas, microwave integrated circuits, reflectarrays, Gaussian beam solutions, millimeter wave antennas, near-field measurements, electromagnetic characterization of materials, innovative radar antennas and technologies.

Antonio BORGIA was born in Reggio Calabria (Italy). He received the Laurea degree in Computer Engineering from the University of Calabria in 2008 and PhD in System and Computer Engineering at the University of Calabria in 2013. He is Member of IEEE, Member of CNIT (Consorzio Nazionale Interuniversitario per le Telecomunicazioni) and SIEm (Società Italiana di Elettromagnetismo). His research interests are focused on millimeter-wave antennas and technologies, printed antennas, reflectarrays. He has (co)authored more than 50 contributions in international journals and conferences.

Antonio RAFFO received the Master degree in Electronic Engineering from the University of Calabria in 2012. From 2012 to 2014 he worked at the Department of Informatics, Modelling, Electronic and System Engineering within a National Italian Project on radar techniques for landslides risk mitigation. Currently, he is a PhD student in ICT at the University of Calabria. His research interests are focused on electromagnetic techniques for biomedical sensing, electromagnetic characterization of materials, software defined radio applications and reconfigurable RF solutions. He has coauthored different contributions in national and international journal and conferences. 